\title{
Neurology
}

\section{Antithrombotic medications and the etiology of intracerebral hemorrhage: MUCH-Italy}

Alessandro Pezzini, Mario Grassi, Maurizio Paciaroni, et al.

Neurology 2014;82;529-535 Published Online before print January 15, 2014

DOI 10.1212/WNL.0000000000000108

This information is current as of January 15, 2014

The online version of this article, along with updated information and services, is located on the World Wide Web at:

http://www.neurology.org/content/82/6/529.full.html

Neurology ${ }^{\circledR}$ is the official journal of the American Academy of Neurology. Published continuously since 1951, it is now a weekly with 48 issues per year. Copyright @ 2014 American Academy of Neurology. All rights reserved. Print ISSN: 0028-3878. Online ISSN: 1526-632X.

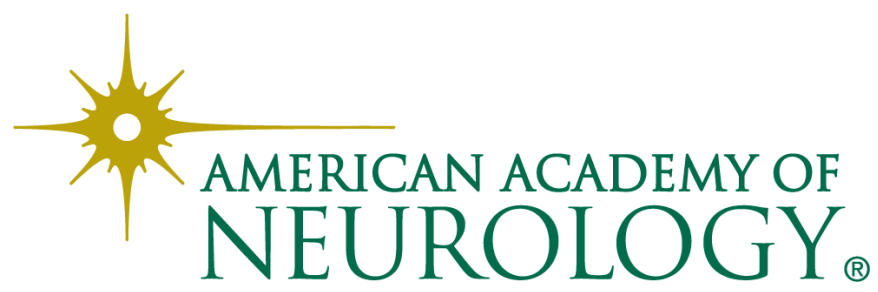


Alessandro Pezzini, MD

Mario Grassi, PhD

Maurizio Paciaroni, MD

Andrea Zini, MD

Giorgio Silvestrelli, MD, $\mathrm{PhD}$

Elisabetta Del Zotto, $\mathrm{MD}, \mathrm{PhD}$

Valeria Caso, MD, $\mathrm{PhD}$

Maria Luisa Dell'Acqua, MD

Alessia Giossi, MD

Irene Volonghi, MD

Anna Maria Simone, MD

Alessia Lanari, MD, PhD

Paolo Costa, MD

Loris Poli, MD

Andrea Morotti, MD

Valeria De Giuli, MD

Daniele Pepe, $\mathrm{PhD}$

Massimo Gamba, MD

Alfonso Ciccone, MD

Marco Ritelli, PhD

Marina Colombi, PhD

Giancarlo Agnelli, MD,

$\mathrm{PhD}$

Alessandro Padovani, $\mathrm{MD}, \mathrm{PhD}$

On behalf of the

Multicenter Study on Cerebral Hemorrhage in Italy (MUCH-Italy) Investigators

Correspondence to Dr. Pezzini:

ale_pezzini@hotmail.com or alessandro.pezzini@med.unibs.it

Supplemental data at www.neurology.org

\section{Antithrombotic medications and the etiology of intracerebral hemorrhage}

MUCH-Italy

\section{ABSTRACT}

Objective: To test the hypothesis that the effect of antithrombotic medications on the risk of intracerebral hemorrhage $(\mathrm{ICH})$ varies according to the location of the hematoma.

Methods: Consecutive patients with ICH were enrolled as part of the Multicenter Study on Cerebral Hemorrhage in Italy (MUCH-Italy). Multivariable logistic regression models served to examine whether risk factors for $\mathrm{ICH}$ and location of the hematoma (deep vs lobar) predict treatmentspecific ICH subgroups (antiplatelets-related ICH and oral anticoagulants [OACs]-related ICH).

Results: A total of 870 (313 lobar $\mathrm{ICH}, 557$ deep ICH) subjects were included. Of these, 223 (25.6\%) were taking antiplatelets and 77 (8.8\%) OACs at the time of stroke. The odds of antiplatelet-related $\mathrm{ICH}$ increased with aging (odds ratio [OR] 1.05; 95\% confidence interval $[\mathrm{Cl}$ 1.03-1.07) and hypertension (OR 1.86; 95\% Cl 1.22-2.85) but had no relation with the anatomical location of $\mathrm{ICH}$. Conversely, lobar location of the hematoma was associated with the subgroup of OAC-related ICH (OR 1.70; 95\% Cl 1.03-2.81) when compared to the subgroup of patients taking no antithrombotic medications. Within the subgroup of patients taking OACs, international normalized ratio (INR) values were higher in those with lobar $\mathrm{ICH}$ as compared to those with deep ICH $(2.8 \pm 1.1$ vs $2.2 \pm 0.8 ; p=0.011)$. The proportion of patients with lobar hematoma increased with increasing intensity of anticoagulation, with a $\sim 2$-fold increased odds of lobar compared to deep ICH (odds 2.17; $p=0.03$ ) in those exposed to overanticoagulation (INR values > 3.0).

Conclusions: OACs, as opposed to antiplatelets, predispose to lobar location of brain hematomas according to a dose-response relationship. Neurology ${ }^{\circledR} 2014 ; 82: 529-535$

\section{GLOSSARY}

$\mathbf{B M I}=$ body mass index; $\mathbf{B P}=$ blood pressure; $\mathbf{C A A}=$ cerebral amyloid angiopathy; $\mathbf{C l}=$ confidence interval; $\mathbf{I C H}=$ intracerebral hemorrhage; INR = international normalized ratio; $\mathbf{M U C H}$-Italy = Multicenter Study on Cerebral Hemorrhage in Italy; OAC $=$ oral anticoagulant

Antithrombotic medications are a highly effective therapy for the prevention of thromboembolic strokes in common clinical situations. However, the increasing use of both antiplatelet and oral anticoagulant $(\mathrm{OAC})$ agents in an aging population has been associated with an increased risk of intracerebral hemorrhage (ICH), ${ }^{1-4}$ with the annual incidence ranging from $0.02 \%$ to $0.47 \%$ in patients taking a single antiplatelet agent to $0.3 \%-0.6 \%$ in those on OAC therapy. ${ }^{5,6}$ The prevention of $\mathrm{ICH}$ in patients with antithrombotic medications is therefore critical, and the identification of risk factors for bleeding is an important practical issue. Data are needed to determine how specific markers may contribute to individualized risk prediction in order to make antithrombotics as safe and effective as possible. Several lines of evidence support the hypothesis that age-related disorders of cerebral small vessels are closely linked to this rare but devastating complication of antithrombotics use. In other terms, antithrombotic medications

From the Dipartimento di Scienze Cliniche e Sperimentali, Clinica Neurologica (A. Pezzini, P.C., L.P., A.M., V.D.G., A. Padovani), and Divisione di Biologia e Genetica, Dipartimento di Medicina Molecolare e Traslazionale (M.R., M.C.), Università degli Studi di Brescia; Dipartimento di Scienze del Sistema Nervoso e del Comportamento (M. Grassi, D.P.), Unità di Statistica Medica e Genomica, Università di Pavia; Stroke Unit and Divisione di Medicina Cardiovascolare (M.P., V.C., G.A.), Università di Perugia; Stroke Unit (A.Z., M.L.D., A.M.S.), Clinica Neurologica, Nuovo Ospedale Civile "S. Agostino Estense," AUSL Modena; U.O di Neurologia (G.S., A.L., A.C.), Ospedale “C. Poma," Mantova; U.O. di Recupero e Rieducazione Funzionale (E.D.Z.), IRCCS Fondazione Don Gnocchi, Rovato; U.O Neurologia (A.G., I.V.), Istituto Clinico "S. Anna,” Brescia; and Stroke Unit (M. Gamba), Neurologia Vascolare, Spedali Civili di Brescia, Brescia, Italy.

Coinvestigators are listed on the Neurology ${ }^{\circledR}$ Web site at www.neurology.org.

Go to Neurology.org for full disclosures. Funding information and disclosures deemed relevant by the authors, if any, are provided at the end of the article. 
per se might not cause ICH if cerebral vessels are intact, but the presence of microangiopathy, rendering small vessels brittle and fragile, is a plausible causal or predisposing factor for bleeding. In this regard, sparse reports have suggested that cerebral amyloid angiopathy (CAA) may be a stronger predictor of antithrombotic-associated $\mathrm{ICH}$ than hypertensive microangiopathy, ${ }^{7-10}$ but some recent observations have questioned this assumption. ${ }^{11,12}$ Thus, any specific relation has not yet been established. The Multicenter Study on Cerebral Hemorrhage in Italy (MUCH-Italy) provides the opportunity to investigate this issue owing to its large sample size, the homogeneous demographic characteristics and clinical phenotype of the subjects included, and the standard diagnostic workup. Therefore, we aimed to evaluate whether 1) antithrombotic medications have differential influence on specific small cerebral vessel pathology, using hemorrhage location (deep vs lobar) to categorize the likely etiology, and 2) any doseeffect relationship of anticoagulation may further predispose to bleeding, in a cohort of Italian stroke patients with $\mathrm{ICH}$.

METHODS Study group. MUCH-Italy is a countrywide network of neurologic centers aimed at recruiting patients with cerebral hemorrhage in the setting of a hospital-based, multicenter, observational study, as previously described..$^{13}$ For the purpose of the present analysis, we screened datasets from patients with acute $\mathrm{ICH}$ consecutively admitted to 4 hospitals between January 2002 and July 2011. Eligibility for study participation required neuroimaging (CT or MRI) confirmation of hemorrhagic stroke. Exclusion criteria included the presence of trauma, brain tumor, hemorrhagic transformation of a cerebral infarction, vascular malformation, or any other perceived cause of secondary ICH. ICH location was assigned based on admission CT scan by stroke neurologists at each participating center. ICH isolated to the cortex (with or without involvement of subcortical white matter) and cerebellar hematomas were defined as lobar $\mathrm{ICH}$, while ICH selectively involving the thalamus, basal ganglia, or brainstem was defined as deep (nonlobar) ICH. Multiple concurrent bleeds involving deep and lobar territories were defined as mixed ICH and represented an exclusion criterion. Demographic and clinical information, as well as neuroimaging data, were collected prospectively and ascertained by neurologists in each center. International normalized ratio (INR) was determined in each patient at admission as part of routine laboratory testing.

Standard protocol approvals, registrations, and patient consents. The study was approved by relevant local authorities at each study site. Written informed consent was obtained from all patients (or next of kin).

Risk factor definition. Subjects were classified as current smokers if they were currently smoking one or more cigarettes per day on a regular basis. Hypertension was defined as systolic blood pressure (BP) $>140 \mathrm{~mm} \mathrm{Hg}$ or diastolic $\mathrm{BP}>90 \mathrm{~mm}$ $\mathrm{Hg}$ out of the acute phase or using pharmacologic treatment for hypertension. Hypercholesterolemia was considered as cholesterol $>240 \mathrm{mg} / \mathrm{dL}$ out of the acute phase or using pharmacologic treatment to lower blood lipids. Diabetes was defined as fasting glucose levels $>125 \mathrm{mg} / \mathrm{dL}$ out of the acute phase or current treatment with antidiabetic drugs. Body mass index (BMI) was calculated as weight in kilograms divided by the square of the height in meters $\left(\mathrm{kg} / \mathrm{m}^{2}\right)$ and subjects dichotomized into obese $\left(\mathrm{BMI} \geq 30.0 \mathrm{~kg} / \mathrm{m}^{2}\right)$ and nonobese $\left(\mathrm{BMI}<30.0 \mathrm{~kg} / \mathrm{m}^{2}\right)$. Based on daily alcohol consumption, subjects were dichotomized into excessive drinkers $(>45 \mathrm{~g}$ of alcohol) and light to moderate drinkers/nondrinkers. We also collected information on atrial fibrillation (medical history or electrocardiographic findings at admission), atherosclerotic peripheral arterial disease (medical history), coronary artery disease (medical history of angina, myocardial infarction, coronary artery bypass graft, or percutaneous transluminal coronary angioplasty), history of previous stroke or TIA (based on clinical history), and pre-ICH medications (warfarin, aspirin or other antiplatelet agents, antihypertensive agents, oral hypoglycemic agents or insulin, and statins). ${ }^{13}$ Data were obtained from interviews with patients, next of kin, or attending physicians or general practitioners.

Statistical analyses. Differences among the treatment groups (ICHs unrelated to antithrombotic medications, antiplateletrelated $\mathrm{ICH}$ s, and $\mathrm{OAC}$-related $\mathrm{ICH}$ ) were examined with the $\chi^{2}$ test, median test, and analysis of variance $F$ test, when appropriate. Categorical (multinomial) logistic regression model was performed to examine the conditional effect of risk factors (hypertension, diabetes, hypercholesterolemia, smoking, alcohol consumption) and location of the hematoma (deep vs lobar) in the prediction of ICH subgroups, adjusted for age and sex (model 1). Since both CAA and hypertensive vasculopathy may be involved in the pathogenesis of cerebellar hemorrhages, ${ }^{14}$ we conducted a separate analysis after exclusion of the cerebellar ICH cases from the study group, to minimize their potentially confounding effect (model 2). Finally, in order to investigate any dose effect of anticoagulant medications, we tested the impact of specific INR categories (INR $\leq 1.2 ; 1.2<$ INR $\leq$ $2.0 ; 2.0<\mathrm{INR} \leq 3.0$; INR $>3.0$ ) on the location of the hematoma within the subgroup of patients with OAC-related ICH using the $4 \times 2$ frequency table. Results are given as ORs (as measures of disease risk for $\mathrm{ICH}$-covariate associations) with $95 \%$ confidence intervals (CIs). A $p$ value $<0.05$ on 2-sided test was considered significant. Data were analyzed using SPSS v. 16 (www.spss.com).

RESULTS A total of 870 patients with ICH fulfilled the inclusion criteria (mean age $72.4 \pm 13.0$ years; $55.7 \%$ male). A total of 313 (36.0\%) had lobar ICH, while 557 (64.0\%) had deep ICH. A total of 300 (34.5\%) patients were on treatment with antithrombotic medications at the time of stroke occurrence, including $223(25.6 \%)$ patients taking antiplatelet drugs and 77 (8.8\%) taking OACs (5 patients using a combination of antiplatelet agents and OACs were categorized as OAC users). No patient was on treatment with other antithrombotic agents (i.e., heparin) before admission. The characteristics of the study group are summarized in table 1 , stratified by antithrombotic medications. Overall, patients treated with antithrombotics were older and more frequently 
Table 1 Demographic and clinical characteristics of the study group

\begin{tabular}{|c|c|c|c|c|}
\hline & $\begin{array}{l}\text { No antithrombotic } \\
\text { therapy }(n=570)\end{array}$ & $\begin{array}{l}\text { Antiplatelet-related } \\
\mathrm{ICH}(\mathrm{n}=223)\end{array}$ & $\begin{array}{l}\text { OAC-related ICH } \\
(n=77)\end{array}$ & $p$ Value \\
\hline Age, $y$, mean $\pm S D$ & $69.8 \pm 13.9$ & $77.2 \pm 9.5$ & $78.1 \pm 8.8$ & 0.002 \\
\hline Female & $239(41.9)$ & $111(49.8)$ & 35 (45.5) & 0.132 \\
\hline $\mathrm{BMI} \geq 30 \mathrm{~kg} / \mathrm{m}^{2}$ & 202 (35.8) & 72 (32.3) & 25 (32.5) & 0.592 \\
\hline Coronary artery disease & $48(8.5)$ & 69 (31.1) & $16(20.8)$ & $<0.001$ \\
\hline Brain ischemia & 20 (3.5) & $44(19.8)$ & $17(22.1)$ & $<0.001$ \\
\hline Atrial fibrillation & 20 (3.5) & 48 (21.6) & $50(66.7)$ & $<0.001$ \\
\hline Peripheral arterial disease & $13(2.3)$ & 5 (2.2) & $6(7.8)$ & 0.019 \\
\hline Hypertension & & & & $<0.001$ \\
\hline Nonhypertensive & $152(26.8)$ & 34 (15.2) & $16(20.8)$ & \\
\hline Hypertensive on treatment & $299(52.7)$ & $172(77.1)$ & $52(67.5)$ & \\
\hline Hypertensive not on treatment & $116(20.5)$ & $17(7.6)$ & 9 (11.7) & \\
\hline Diabetes & & & & 0.642 \\
\hline Nondiabetic & 470 (82.9) & $180(80.7)$ & $59(76.6)$ & \\
\hline Diabetic on treatment & 69 (12.2) & 32 (14.3) & $12(15.6)$ & \\
\hline Diabetic not on treatment & $28(4.9)$ & $11(4.9)$ & $6(7.8)$ & \\
\hline Cholesterolemia & & & & 0.012 \\
\hline Nonhypercholesterolemic & $455(80.2)$ & $171(76.7)$ & $66(85.7)$ & \\
\hline $\begin{array}{l}\text { Hypercholesterolemic on treatment } \\
\text { with statins }\end{array}$ & $51(9.0)$ & $36(16.1)$ & $9(11.7)$ & \\
\hline Hypercholesterolemic not on treatment & 59 (10.4) & $16(7.2)$ & 2 (2.6) & \\
\hline Current smoking & $83(14.7)$ & $28(12.6)$ & $5(6.5)$ & 0.128 \\
\hline Alcohol, excessive drinking & $93(16.3)$ & 30 (13.5) & 11 (14.3) & 0.580 \\
\hline \multicolumn{5}{|l|}{ ICH location } \\
\hline Deep & $377(66.1)$ & $139(62.3)$ & 41 (53.2) & 0.072 \\
\hline Lobar & 193 (33.9) & $84(37.7)$ & $36(46.8)$ & \\
\hline
\end{tabular}

Abbreviations: $\mathrm{BMI}=$ body mass index $\mathrm{ICH}=$ intracerebral hemorrhage; $\mathrm{OAC}=$ oral anticoagulant.

Data are $n(\%)$ unless otherwise noted.

female and had a higher prevalence of risk factors (in particular, hypertension) and comorbidities (previous brain ischemia, ischemic heart disease, and atrial fibrillation) than patients who were not on treatment.

The majority of antiplatelet users were on treatment with aspirin $(\mathrm{n}=207,90.8 \%$; ticlopidine, $\mathrm{n}=17,7.5 \%$; clopidogrel, $\mathrm{n}=3,1.3 \%$; aspirin plus dipyridamole, $\mathrm{n}=1,0.4 \%)$. Among OAC users, 7 (9.1\%) had INR values $\leq 1.2,22(28.6 \%)$ had INR values 1.2-2.0, 29 (37.7\%) had INR values 2.0-3.0, and $19(24.7 \%)$ had INR values $>3.0$ (figure 1 ). The mean INR value in this subgroup was $2.5 \pm 1.0$ and was higher in patients with lobar ICH as compared to those with deep ICH $(2.8 \pm 1.1$ vs $2.2 \pm 0.8$; $p=$ $0.011)$. The mean INR value in the subgroup of patients exposed to overanticoagulation (INR $>3$ ) was $4.0 \pm 0.8$.

As summarized in table 2, aging had a similar effect on increasing the risk of disease in the group of antiplatelet-related ICH (OR 1.05; 95\% CI 1.03$1.07)$ as well as in that of OAC-related ICH (OR
1.06; 95\% CI 1.03-1.09) when compared to the reference group of patients who were taking no antithrombotic medications at the time of stroke occurrence. In addition, we observed an increase in the risk of ICH with hypertension, which was significant only in the subgroup of patients with antiplatelet-related ICH (OR 1.86; 95\% CI 1.22-2.85). None of the other traditional vascular risk factors had any independent influence on the risk of antithrombotic-related ICH. Lobar location of the hematoma was associated with the subgroup of OAC-related ICH (OR 1.70; 95\% CI 1.03-2.81), as opposed to what was observed for deep ICH, while hemorrhage location had no significant association with the subgroup of antiplateletrelated ICH (model 1). Results remained substantially unchanged when data were reanalyzed after removing the subgroup of patients with cerebellar hemorrhages (model 2, not shown). Within the subgroup of OAC-related ICH, the frequency of ICH increased in both deep and lobar brain regions with increasing INR values up to 3.0, with no difference between the 2 
Figure 1 Proportion of patients in various categories of international normalized ratio values at admission

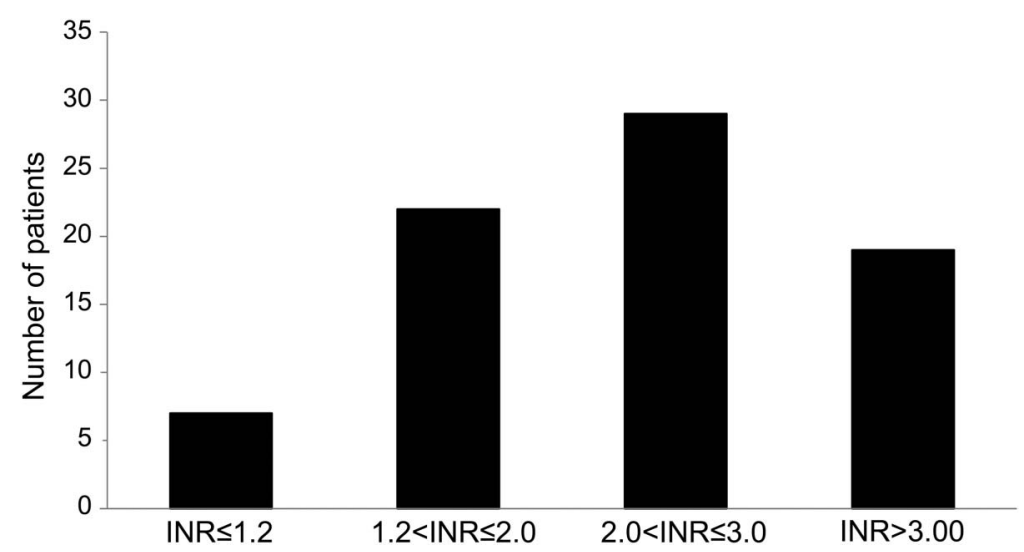

Within the subgroup of oral anticoagulant-related intracerebral hemorrhage. INR = international normalized ratio.

groups $(p>0.05)$, but it decreased in deep structures when INR values were $>3.0(p<0.05$; figure $2 \mathrm{~A})$. The proportion of patients with lobar ICH increased with increasing intensity of anticoagulation according to a direct dose-response relationship (figure $2 \mathrm{~B}$ ), which resulted in a $\sim 2$-fold increased odds of lobar $\mathrm{ICH}$ compared to deep ICH (odds 2.17; $p=0.03$ ) in the subgroup with the highest level of anticoagulation $(\mathrm{INR}>3.0)$.

DISCUSSION The precise contribution of antithrombotic medications to the location of $\mathrm{ICH}$ has not yet been determined. Our study, involving a large cohort of patients with $\mathrm{ICH}$, indicates that antiplatelet agents have a negligible influence on the site of bleeding, their effect probably being overcome by that of other predisposing conditions, such as aging and hypertension, while, conversely, the use of OACs predisposes to lobar location of brain hematomas.

These findings confirm and extend those of previous studies on the relation between antithrombotic medications and hemorrhagic stroke and add further

\begin{tabular}{|c|c|c|c|c|c|}
\hline \multirow[t]{2}{*}{ Table 2} & \multicolumn{5}{|c|}{$\begin{array}{l}\text { Conditional effect of age, sex, risk factors (hypertension, diabetes, } \\
\text { hypercholesterolemia, smoking, alcohol consumption), and location of } \\
\text { the hematoma (deep ICH vs lobar ICH) in the prediction of antiplatelet- } \\
\text { related ICH and oral anticoagulant-related ICH (model 1) }\end{array}$} \\
\hline & & $\begin{array}{l}\text { Antip } \\
\text { ICHs } \\
\text { antitl } \\
\text { ICHs }\end{array}$ & $\begin{array}{l}\text {-related } \\
\text { otic-related }\end{array}$ & $\begin{array}{l}\text { Oral a } \\
\text { relate } \\
\text { antith } \\
\text { ICHs }\end{array}$ & $\begin{array}{l}\text { agulant- } \\
\text { s vs non- } \\
\text { otic-related }\end{array}$ \\
\hline \multicolumn{2}{|l|}{ Model 1} & OR & $95 \% \mathrm{Cl}$ & OR & $95 \% \mathrm{Cl}$ \\
\hline \multicolumn{2}{|c|}{ Age, per year } & 1.05 & $1.03-1.07$ & 1.06 & $1.03-1.09$ \\
\hline \multicolumn{2}{|c|}{ Hypertension } & 1.86 & $1.22-2.85$ & 1.31 & $0.72-2.38$ \\
\hline \multicolumn{2}{|c|}{ ICH location, lobar vs deep } & 1.17 & $0.83-1.64$ & 1.70 & $1.03-2.81$ \\
\hline
\end{tabular}

Abbreviations: $\mathrm{Cl}=$ confidence interval; $\mathrm{ICH}=$ intracerebral hemorrhage; $\mathrm{OR}=$ odds ratio. Only significant values are reported. data on the question of whether the contribution of these agents, especially OACs, to cerebral bleeding might vary by anatomical location. First, they confirm that ICH is common in patients treated with antithrombotic drugs, independent of the anatomical location of bleeding. Furthermore, in our series like in prior studies, ${ }^{8,15,16}$ a relevant proportion of $\mathrm{ICH}$ among those on OACs occurred when the INR values were in the therapeutic range. Second, they support previous observations that OAC-related $\mathrm{ICH}$ s occur with a slightly more frequent lobar location..$^{7-10}$ However, data on the impact of specific small-vessel arteriopathies on OAC-related $\mathrm{ICH}$ are scarce, mainly derived from studies including small case series, sometimes recording individual history of OAC use without taking into consideration the intensity of anticoagulation, ${ }^{7}$ including patients receiving heparin at the time of stroke, ${ }^{8,11}$ or aimed at addressing different issues, ${ }^{8,9,11}$ with only a few notable exceptions. ${ }^{10,12}$ In this regard, a novel finding from our data is the evidence of a direct dose-response relationship between OAC treatment and lobar ICH, as illustrated by the increasing number of patients in this subgroup as the INR values increase. We speculate that OACs affect CAA and hypertensive arteriolosclerosis equally when INR values are within the therapeutic range, but that they exert a differential impact on the 2 cerebral microangiopathies, with a greater effect on cortical-subcortical vessels, in case of excessive anticoagulation. As a consequence of this, there might be an individual threshold of INR values over which the influence of OACs on hematoma location becomes more evident. It remains unclear whether this is a causal association, or, more likely, the end result of a dynamic interplay among several conditions including the underlying bleeding-prone small-vessel disease, the direct effect of these agents on the clotting cascade, and other unknown factors. Though unproven, a number of histologic findings provide biologic support to this view. Arteriolar wall thinning, interposition of amyloid deposits between smooth muscle cells, dilated perivascular spaces, and microaneurysms are frequent findings in CAA involving lobar brain regions, whereas thickening of the vessel wall caused by lipohyalinosis in response to chronic hypertension is the pathologic marker of arteriolosclerosis in deep regions. It is likely that these abnormalities might render cortical-subcortical vessels more vulnerable to rupture and with less potential for tamponade compared to deep perforating arteries in the presence of excessive anticoagulation. ${ }^{17,18}$ In addition, evidence supporting a link between CAA and $\mathrm{OAC}-\mathrm{ICH}$ includes the demonstration that the $A P O E$ \&2 allele, a known genetic risk factor of CAA-related lobar $\mathrm{ICH},{ }^{19,20}$ is more common in warfarin-associated $\mathrm{ICH}$ than in control patients on 


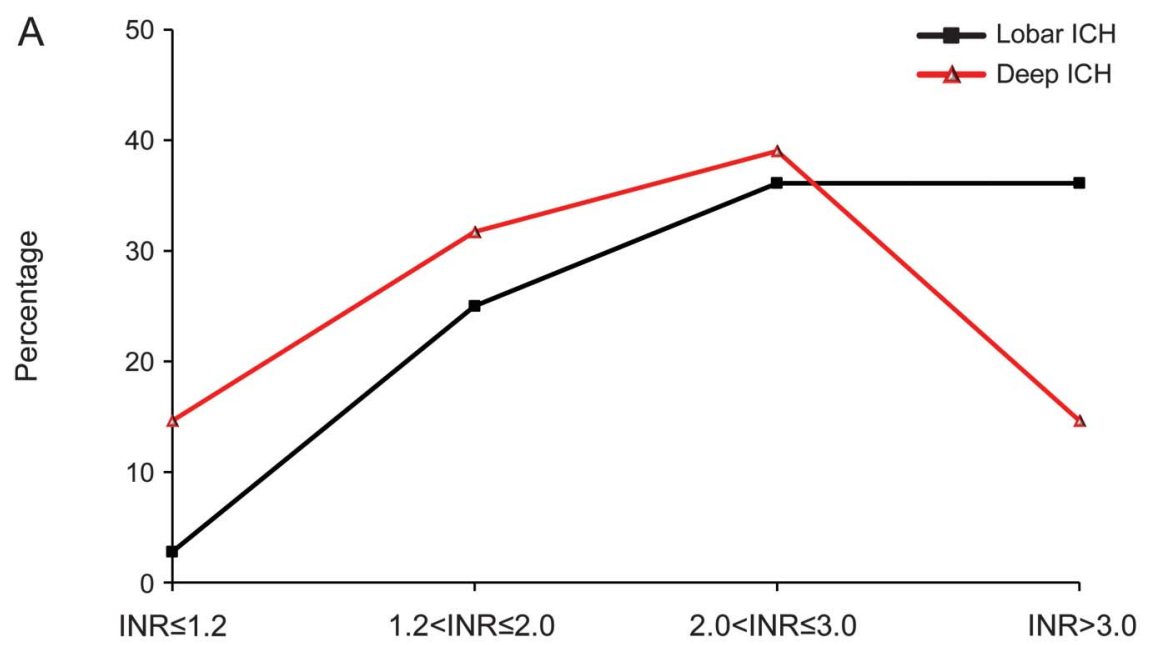

B

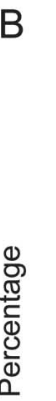

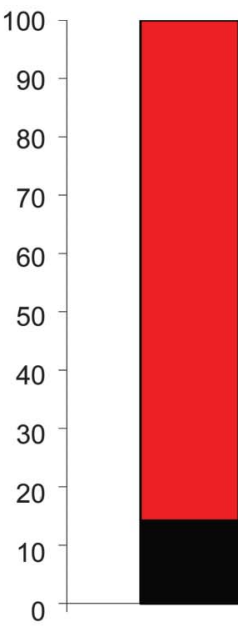

INR $\leq 1.2$

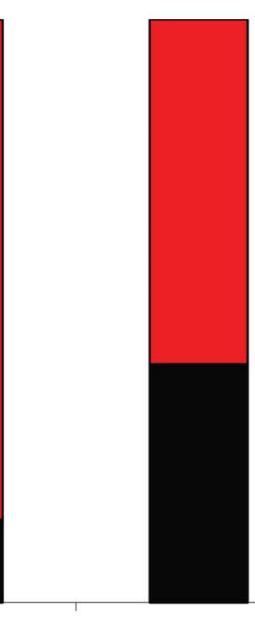

$1.2<I N R \leq 2.0$

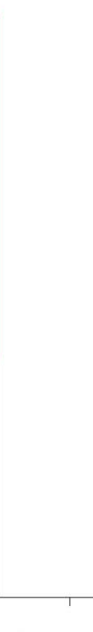

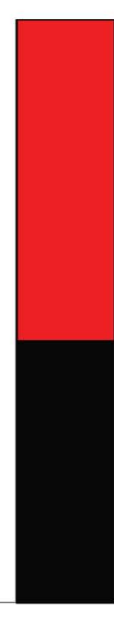

$2.0<I N R \leq 3.0$

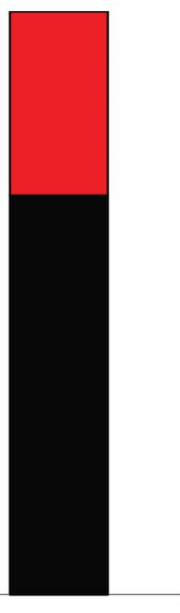

INR $>3.0$

Deep ICH

Lobar ICH

C

$\begin{array}{ll}\text { Lobar ICH, no. } & 1 \\ \text { Deep ICH, no. } & 6 \\ \text { Odds lobar/deep } & 0.16 \\ \text { OR lobar/deep } & 1 \\ 95 \% \mathrm{Cl} & 1 \\ p \text {-value } & 1\end{array}$

9

13

0.69

4.15

$0.42-41$

0.22
13

16

0.81

4.87

$0.52-46$

0.16
13

6

2.16

13

1.27-133

0.03

(A) Percentage of international normalized ratio (INR) values conditional to the location of the hematoma. (B) Percentage of lobar and deep intracerebral hemorrhages (ICHs) conditional to INR values. (C) $4 \times 2$ frequency table of lobar/deep ICH by INR values with odds ratio (OR), 95\% confidence interval (CI), and $p$ values for lobar/deep.

warfarin without $\mathrm{ICH},{ }^{8}$ and that individual cases of $\mathrm{ICH}$ following anticoagulation or coronary thrombolysis revealed advanced CAA on autopsy. ${ }^{21,22}$ Our findings are in apparent disagreement with those derived from the PITCH study by DequatrePonchelle et al. ${ }^{12}$ who found no influence of OACs on the anatomical distribution of ICH but a significant effect of these compounds on the volume of deep brain hematomas. This would support the conclusion that deep perforating arteries are more sensitive to anticoagulation than cortical-subcortical vessels. Such a discrepancy might be explained by the slightly different definition of deep and lobar ICH in the 2 studies, as well as by the potential biases in the measurement of hematoma volumes, as pointed out by the authors themselves, and, even more important, by the fact that regression models in the PITCH study did not include adjustment for hypertension. ${ }^{12}$ 
Furthermore, because existing evidence suggests that both CAA and hypertension can be responsible for intracranial bleeding in the cerebellum, ${ }^{14}$ analyses on the relation between risk factors and $\mathrm{ICH}$ location should consider cerebellar hemorrhages as a potential source of bias and take account of this.

Several strengths of the present study should be noted, including the large number of participants, the homogeneous demographic characteristics and clinical phenotype of the cohort, and the standardized diagnostic workup and evaluation of risk factors. Some limitations also should be considered. First, because the MUCH-Italy is a hospitalbased study, the results might be susceptible to hospital referral selection bias. However, inaccurate capture of the incident cases is highly unlikely as all patients with acute cerebral hemorrhage in the geographic areas involved in the study are usually referred to the participating centers. Second, because of the relatively small numbers of subjects in specific subgroups, such as in the upper INR strata, some results should be viewed with caution. Third, recruitment time period was long, during which improvement in diagnostic facilities and preventive medications has occurred. In particular, because brain MRI was not part of the routine imaging protocol during the first years of the study, only a small proportion of patients have these data available. This precluded the inclusion of neuroradiologic markers that could be of interest, such as brain microbleeds, ${ }^{23}$ in the final analysis. Fourth, we cannot theoretically exclude a classification bias in categorizing patients' medical history or the potential influence of other, undetected medical conditions (i.e., chronic kidney disease) on the results of the study.

In spite of these limitations, our findings provide evidence that OACs, as opposed to antiplatelet agents, increase the propensity to cerebral bleeding to a higher degree in lobar than in deep brain regions. This differential effect should be considered in future trials with new antithrombotic agents, as well as with any new molecules interfering with clot formation and, in clinical practice, when the potential benefits of OACs as regards stroke prevention are to be balanced against their bleeding risk. We hypothesize that a similar effect will be seen with novel OACs or with multiple antithrombotic therapies, but further dedicated studies are needed.

\section{AUTHOR CONTRIBUTIONS}

Dr. Pezzini: manuscript drafting/revising, study design, data analysis and interpretation, data acquisition, statistical analysis, study supervision. Dr. Grassi, Dr. Pepe: data analysis and interpretation, statistical analysis. Dr. Paciaroni, Dr. Zini, Dr. Silvestrelli: manuscript drafting/revising, study design, data acquisition. Dr. Del Zotto, Dr. Caso, Dr. Dell'Acqua, Dr. Giossi, Dr. Volonghi, Dr. Simone, Dr. Lanari, Dr. Costa, Dr. Poli, Dr. Gamba,
Dr. Morotti, Dr. De Giuli, Dr. Ciccone, Dr. Ritelli, Dr. Colombi, Dr. Agnelli: manuscript drafting/revising, data acquisition. Dr. Padovani: manuscript drafting/revising, study design, study supervision.

\section{STUDY FUNDING}

No targeted funding reported.

\section{DISCLOSURE}

The authors report no disclosures relevant to the manuscript. Go to Neurology.org for full disclosures.

Received July 10, 2013. Accepted in final form November 5, 2013.

\section{REFERENCES}

1. Lauer A, Pfeischifter W, Schaffer CB, Lo EH, Foerch C. Intracerebral haemorrhage associated with antithrombotic treatment: translational insights from experimental studies. Lancet Neurol 2013;12:394-405.

2. He J, Whelton PK, Vu B, Klag MJ. Aspirin and risk of hemorrhagic stroke: a meta-analysis of randomized controlled trials. JAMA 1998;280:1930-1935.

3. Huhtakangas J, Tetri S, Juvela $S$, et al. Effect of increased warfarin use on warfarin-related cerebral haemorrhage: a longitudinal population-based study. Stroke 2011;42: 2431-2435.

4. Flaherty ML, Kissela B, Woo D, et al. The increasing incidence of anticoagulant-associated intracerebral haemorrhage. Neurology 2007;68:116-121.

5. Buresly K, Eisenberg M, Zhang X, et al. Bleeding complications associated with combinations of aspirin, thienopyridine derivatives, and warfarin in elderly patients following acute myocardial infarction. Arch Intern Med 2005;165: 784-789.

6. Chimowitz M, Lynn M, Howlett-Smith H, et al. Comparison of warfarin and aspirin for symptomatic intracranial arterial stenosis. N Engl J Med 2005;352:1305-1316.

7. Lipton RB, Berger AR, Lesser ML, Lantos G, Portenoy RK. Lobar vs thalamic and basal ganglion haemorrhage: clinical and radiographic features. J Neurol 1987;234:86-90.

8. Rosand J, Eckman MH, Knudsen KA, Singer DE, Greenberg SM. The effect of warfarin and intensity of anticoagulation on outcome of intracerebral haemorrhage. Arch Intern Med 2004;164:880-884.

9. Cucchiara B, Messe S, Sansing L, Kasner S, Lyden P; for the CHANT Investigators. Hematoma growth in oral anticoagulant related intracerebral hemorrhage. Stroke 2008;39;2993-2996.

10. Maas MB, Rosenberg NF, Kosteva AR, Prabhakaran S, Naidech AM. Coagulopathy disproportionately predisposes to lobar intracerebral hemorrhage. Neurocrit Care 2013;18:166-169.

11. Flaherty ML, Haverbusch M, Sekar P, et al. Location and outcome of anticoagulant-associated intracerebral hemorrhage. Neurocrit Care 2006;5:197-201.

12. Dequatre-Ponchelle N, Hénon H, Pasquini M, et al. Vitamin $\mathrm{K}$ antagonists-associated cerebral hemorrhages: what are their characteristics? Stroke 2013;44:350-355.

13. Pezzini A, Grassi M, Paciaroni M, et al; Multicentre Study on Cerebral Hemorrhage in Italy (MUCH-Italy) Investigators. Obesity and the risk of intracerebral hemorrhage: the Multicentre Study on Cerebral Hemorrhage in Italy. Stroke 2013;44:1584-1589.

14. Lang EW, Ren Ya Z, Preul C, et al. Stroke pattern interpretation: the variability of hypertensive versus amyloid 
angiopathy hemorrhage. Cerebrovasc Dis 2001;12: 121-130.

15. Flaherty ML, Tao H, Haverbusch $\mathrm{M}$, et al. Warfarin use leads to larger intracerebral hematomas. Neurology 2008; 71:1084-1089.

16. Biffi A, Battey TWK, Ayres AM, et al. Warfarin-related intraventricular hemorrhage: imaging and outcome. Neurology 2011;77:1840-1846.

17. Attems J. Sporadic cerebral amyloid angiopathy: pathology, clinical implications, and possible pathomechanisms. Acta Neuropathol 2005;110:345-359.

18. Revesz T, Ghiso J, Lashley $\mathrm{T}$, et al. Cerebral amyloid angiopathies: a pathologic, biochemical, and genetic view. J Neuropathol Exp Neurol 2003;62:885-898.

19. Nicoll JA, Burnett C, Love S, et al. High frequency of apolipoprotein $\mathrm{E}$ epsilon 2 allele in hemorrhage due to cerebral amyloid angiopathy. Ann Neurol 1997;41: 716-721.

20. Biffi A, Halpin A, Towfighi A, et al. Aspirin and recurrent intracerebral hemorrhage in cerebral amyloid angiopathy. Neurology 2010;75:693-698.

21. Melo TP, Bogousslavsky J, Regli F, Janzer R. Fatal hemorrhage during anticoagulation of cardioembolic infarction: role of cerebral amyloid angiopathy. Eur Neurol 1993;33:9-12.

22. McCarron MO, Nicoll JA. Cerebral amyloid angiopathy and thrombolysis-related intracerebral haemorrhage. Lancet Neurol 2004;3:484-492.

23. Greenberg SM, Vernooij MW, Cordonnier C, et al; for the Microbleed Study Group. Cerebral microbleeds: a guide to detection and interpretation. Lancet Neurol 2009;8:165-174.

\section{AAN Annual Meeting Registration Now Open!}

\section{Connecting All of Neurology with Unparalleled Science, Education, and Networking}

Registration is now open for the upcoming AAN Annual Meeting, coming to Philadelphia, PA, April 26-May 3, 2014. Register early to save with deep discounts to the world's largest gathering of neurologists featuring breakthrough scientific research, premier education programming, and unparalleled networking opportunities.

- Early registration discount deadline: April 3, 2014

- Hotel deadline: March 26, 2014

Visit www.aan.com/view/am14 today!

\section{Neurology ${ }^{\circledR}$ WriteClick: Join the Debate!}

The editors encourage comments about recent articles through WriteClick:

Go to www.neurology.org and click on the "WriteClick" tab at the top of the page. Responses will be posted within 72 hours of submission.

Before using WriteClick, remember the following:

- WriteClick is restricted to comments about studies published in Neurology within the last eight weeks

- Read previously posted comments; redundant comments will not be posted

- Your submission must be 200 words or less and have a maximum of five references; reference one must be the article on which you are commenting

- You can include a maximum of five authors (including yourself) 


\section{Antithrombotic medications and the etiology of intracerebral hemorrhage: \\ MUCH-Italy}

Alessandro Pezzini, Mario Grassi, Maurizio Paciaroni, et al.

Neurology 2014;82;529-535 Published Online before print January 15, 2014

DOI 10.1212/WNL.0000000000000108

This information is current as of January 15, 2014

$\begin{array}{ll}\begin{array}{l}\text { Updated Information \& } \\ \text { Services }\end{array} & \begin{array}{l}\text { including high resolution figures, can be found at: } \\ \text { http://www.neurology.org/content/82/6/529.full.html }\end{array} \\ \text { Supplementary Material } & \begin{array}{l}\text { Supplementary material can be found at: } \\ \text { http://www.neurology.org/content/suppl/2014/01/15/WNL.00000 } \\ \text { 00000000108.DC1.html }\end{array} \\ \text { This article cites } 23 \text { articles, } 8 \text { of which you can access for free } \\ \text { at: } \\ \text { http://www.neurology.org/content/82/6/529.full.html\#\#ref-list-1 } \\ \text { Information about reproducing this article in parts (figures,tables) } \\ \text { or in its entirety can be found online at: } \\ \text { http://www.neurology.org/misc/about.xhtml\#permissions }\end{array}$

